\title{
The Relation of Muscular Activity to the Mental Process*
}

\author{
The Energy That Directs the Movements That Represent Consciousness
}

\author{
By George Van N. Dearborn, A. M. (Harv.) M. D., Ph. D. (Col.)
}

'No adequately develop the relations of muscle to the mental process would require a destructive criticism of the widely accepted notion that the nervous system, and especially the brain-cortex, is the sole physical basi of consciousness. The burden of proving such a thesi rests on those who accept it, and as a student of both the mental process and of the nature of protoplasm, I, for one, see no reason to accept this hereditary ex
cathedra supposition. I wish here only to point out then, partially, the fitness of muscle, e. $g$, to correlate then, partially, the fitness of muscle, e. $\mathrm{g}$, to correlate
in part the ever-amazing inherent tide we know as consciousness.

As all propositions relating to psychological correlation must be, for the present at least, analogical in a measure, those that follow are so, but they also ar inductive, and are based on the latest facts and idea of physiology. They have but little sympathy, indeed, with the apotheosis of the nervous system, now popular, or with even a modification of the notion that the soul has its-(rather uneasy) seat in the pineal gland. 'To those who realize the almost perfect unification of the bodily tissues, such a view is unlikely. This principle of localization will do for urine, for saliva, for bile, but not for body heat, for movement, etc. Above all, it will not sufice for consciousness, unless indee consciousness really be a secretion-and we, every one of us, know better than that. Among the tissues and organs of the body, it is our privilege to inquire the what muscle (muscle-protoplasm unified largely by the nerves into a single and always vital mechanism) has to do with mind.

We cannot stop in this place to discuss the criteria of correlation a priori. Of the protoplasmic nature of muscle and its intimate structure it is important only to note that by its intricate chemical composition, an by its consequent elaborate metabolism, muscle is amply defunate as a correlate of the mental process. No othe bodily tissue has more complexity either in its mole cules, or in the arrangement of these molecules into cells and fibers. If subtlety of metabolism or intricacy of structure be criteria of a physical basis for consciousness, we can probably find in muscle the maximum of each. Inder such conditions we might reasonably expect to find, furthermore, a unique variety of forms of energy, and among them, perhaps, several potential energies which might most closely represent the experience we know as mind.

Consistent motion characterizes Life.

$\Lambda$ criterion of concomitance, perhaps more likely than these just mentioned, exists in the category of motio or movement, and attention must be directed to this for a moment. If one thing more than another characterizes life and its two aspects alike (the menta process and the phenomena of protoplasm), that thin is consistent motion. This is an irreversible timeis consistent motion. This is an irreversible time-
series with its termini hidden from us, but with its actual process the most obvious of all our experiences. Unlike other forms of human protoplasm (excepting leucocytes and cilia), muscle has two sorts of movement: the molecular movements common to all matte (but at their maximum in organic substance), and mechanical or molar movement.

Using its end-products, carbon dioxide and nitrogen as the gauge of the metabolism of muscle, we find it the most active of all the tissues. Muscle will absorb mor oxygen and give out more carbon dioxide and mor heat in doing so, than any other tissue per gramme of weight. From one strongly defensible viewpoint this fact is in itself important, since the liberation of energy seems the closest possible correlate of the menta process in its various degrees of consciousness. But we will pass that for the other certainly much less debatable form of motion, i. e., gross, mechanical, or molar movement (contraction).

muscular tissue always active.

Recent physiological work on muscle has emphasized how literally this tissue may be said to be always active in a mechanical as well as in a molecular, metabolic way. This molar activity is expressed as the "tone" of of life and departs only at death. It is essentially of life and departs only at death. It is essentially a useful partial contraction varying back and forth in a sort of balance, now stronger, now weaker, as
conditions require. Very recent work makes it likely that every bit of muscle tissue, whether "striated" o

*From the American Physical Dducation Review. "unstriated" (distinctions which tend to disappear), has two sorts of contraction: its proper, relatively quick movement, superimposed and based on this slow and rythmic tonal beat. This tonal contraction ha been studied and described in physiological laboratories where the term consciousness expresses scarcely mor than a useless epiphenomenon. But the psycholigist long ago (in the kinesthetic theory of feeling) demonstrated from the "mental side of the curve" just this same thing, practically, in muscle tissue. With the proper apparatus it is easy to demonstrate that in every portion of the body, muscle-tissue by its activity represents every feeling-tone strong enough to be considered as such. These two facts concerning the universality of muscle action strikingly corroborate each other and give to each an explanation lacking without the other. From the purely myological side one finds all muscle always contracting, balancing actively back and forth; from the psychological side we all see feeling to be universally an aspect of consciousness, and always accompanied by somatic movements al over the body. Do not these help explain each other and at the same time unify for us still further the dural aspects, body and mind?

MUSCLES CONCEIVED AS SEPARATE PIECES OF APPARATI'S.

It is easy, especially for the psychologist, perhaps, to think of the muscles as separate pieces of apparatus like pistons or other shortening and lengthening devices, or that they are at least like tools of rubber reacting after being mechanically stretched. Such a mode of conceiving muscle is in fact a natural corollary of the anatomy of muscles as found in the books of a few years back. As seen from the outside, the muscles are just this-separate masses of flesh which somehow or other shorten and draw towards each othe whatever holds their ends. Subjectively and physiologically viewed, how different muscles seem! One of the most marvelous of the marvels of the organism is the muscle fiber, both in the chemistry and the physics of its living matter. No one knows surely how it works, much less its essential structure, but the perfect unification and functional correlation of its activity despite the relative separateness of its muscle-bundles every observer understands.

But the gross voluntary muscles of the bones are only the most conspicuous of the outer muscles of the body. Muscle constitutes almost or quite half the mass of the organism and its all pervasiveness few psychologists have stopped to consider. There are more than 600 striated or "voluntary" muscles, and everywher else in the body (save in the bones, in the nervou system, and in the alveoli of certain glands) smooth muscle tissue is found. All up and down the blood and lymph vessels in almost every minute part of the body, up and down the whole alimentary canal and the ducts and glands attached to it, up and down the whole respiratory system, and the excretory organs and the reproductive organs, in the spleen, in the skin, and in many of the sense organs, smooth or unstriated muscle maintains unceasingly its tonal and occasiona contracting. Thus one properly thinks of the muscles as all-pervading tissues of living matter working continually and everywhere-not by any means as if made up of separate gross parts, inanimate tools which some obscure and hereditary notion of will hidden in a brain cortex uses much as a mason handles a wooden and steel trowel. In psychology especially, muscle should be thought of as a reticulum, a semi-liquid vital tissue, part of whose function in the general life is to conduct the all important movements of the body parallel somehow to the movements in the mental series This widely permeating (fibrillar?) network of muscle fibers is unified and made practically a single organ by the same means by which the other tissues are unified, probably by protoplasmic bridges and certainly by currents of the blood and lymph and the all-bridging nervous system. More and more, the various functional systems of the body unified by these three means at least, are seen to be only inseparable parts of a perfect continuum, both as to use and structure. Muscle surely partakes in that basal generalization that mind no less than life inheres only in unifications. Arnold has lately made this

How autonomous muscle-tissue is, many recent researches have plainly shown. One of the latest at hand is that reported by Wintrebert, who demonstrates in a new way how independent of nerve the contracility of muscle is, proving that this sort of protoplasm performs its inherent function before the nerves have grown into it from the developing nervous centers. Kurdinouski and Franz, separately, offer similar evidence from an entirely different direction, while Bethe, Marinesco, Vermes, Kolmer, Michotte, and especially Dogiel, Loudon and Ramon y Cajal, each by a separate research, using for the most part methods quite new, publish recent work tending to establish yet more firmly the fibrillar nature of the nervous system-as a vast conductive mesh connecting functions outside itself. Long since, Sir Michael Foster, notable among physiologists for the breadth of his vision and the excellence of his judgment, called muscle "the master tissue of the body." How can we continue to ignore all these myopsychic relations? The mere wires of an electric system are not its essential part.

THE WILl NOT SEATED IN TIIE BRAIN.

One no longer, surely, thinks of the "will" as seated in the brain, causing the muscles to contract by its own iniative and through its own agency. In no sense does muscle, in the hierarchy of the tissues, own any inferiority to the nerves. The brain, probably the cerebellum, coördinates the movements and, in case of the voluntary muscles, directs them on the same basis that some of the glands provide them with metabolic enzymes, the intestines with food, the blood with commissary and sewerage service, and the lungs with oxygen. But the muscles, like the glands, the intestines and the lungs, are living protoplasm and we have the right to suppose serve the brain no more than the brain serves them. Each is but a special differentiation of one living substance like the rest of material force and matter, containing no essential inherent tendency to centrality.

If, as we may, we define the personality - the individnal-as a center of purposes, we have a basis for a twofold division of the movements which fulfill its will. On the one hand, primary in philosophic importance, are the acts which directly help the evolution of the world, however little any one act may count in this direction. These are the "voluntary" movements and they are made only with the greater or less attentive effort of consciousness. Beneath these and vegetative in nature, as Starr calls them, are the reflex movements, mostly of the unstriated muscles; these latter refle $\bar{x}$ movements make the voluntary movements possible. Scattered equally through both kinds of muscle are multitudes of both afferent and efferent end-organs of many linds, that properly speaking are parts of the nervous system.

$$
\text { CO-ORDINATION OF TIIE VARIOUS FIBERS. }
$$

Through these is effected the coördination of the various fibers to each other and the organic needs. By what right or reason can it be presumed that these common end-organs, and their nerve fibers and centers "represent consciousness" in case of the voluntary muscles and not in case of the involuntary or reflex muscles? One searches in vain the known facts concerning the paths and centers of the nervous system for any essential differences in the paths or in the tracts devoted to these two kinds of morement, save that the voluntary muscle (because of its necessary connection with the "higher" coördinating centers?) is coördinated in the cortex of the cerebrum as well as in the cerebellum. Such double "representation" in the great neural connecting reticulum of the body may very well stand for a larger share in the attentive consciousness than belongs to the vegetative muscles, because more parts of the body are then involved. Many things, however, indicate that in those large parts of the varied mental process which we call subconsciousness the reflexly or automatically acting portions of the muscle tissue play a very large part. Conscious effort accompanies the coördination of the voluntary muscles, perhaps because the process is a relatively novel one each time, but the reflex muscles, often well-nigh automatic, normally act without drawing the actual attention of the subject. It must not because of that, however, be presumed that they count less in making up the fusion current of the fundamental subconscious aspects of mind.

Did time allow we should like here to consider in deail those most elaborate although unconscious manifestations with which we are all more or less familiar 
in imitation, in somnambulism, and in muscular automatism of many kinds. We should consider, too, some of those still obscure afferent (sensational) aspects of the muscles, especially in abnormal muscular conditions such as those of angina pectoris in the heart mustions such as those of angina pectoris in the heart mus
cle, of colic or cramp in the hollow viscera or tubes, of cle, of colic or cramp in the hollow viscera or tubes, of
the sensory visceral disturbances of hysteria and of paranoia. These derangements, purely muscular i origin, are just beginning to be technically understood in the subtle complexities of muscular composition or structure. Is any one really content to say that it is the brain protoplasm and not the muscle protoplasm that represents aberrations from the normal consciousness like these? And when, in direct sub-conscious imitalike these? And when, in direct sub-conscious imita-
tion, a large group of the fibers of the muscle-reticulum act in a certain way, are you each quite satisfied to imagine, as did the revered Descartes, that a fe grammes of protoplasm in the cerebral cortex knows it all, does it all, and represents withal what little of attentive consciousness appertains? And in the voluntary muscular efforts by which all that is new is accomplished, do muscular cunning and skill and clevis accomplished, do muscular cunning and skill and clev-
erness count for nothing, and indeed mean nothing but erness count for nothing, and indeed mean nothing but
a better brain? Is the subjective consciousness that accompanies the piano playing of a master pianist based wholly on his better sort of brain cortex (a layer of protoplasm similar to that of muscle and only three millimeters thick), without possible relation, save as to a set of tools, to the muscles which alone possess such perfect cunning, and do all the wondrous work? To me, for one, such a supposition seem not merely unlikely, as it is inherently absurd, but, what is of far more importance, it seems assuredly an impeding and gratuitous presumption which the balance of evidence emphatically rejects.

MARVELUUS STRUCTURE •F $\Lambda$ N M MUSCULATURE.

Such are some of the considerations, that arise in one's mind when one considers the marvelous structure of any musculature. They are obviously, in part, the reactionary products of revolt against what we have already called the unwarranted apotheosis of the nervous system, especially of its gray matter. The natural priori presumption of the average child would be. it i likely, that the body in general is conscious, that all protoplasm is the basis of physical life. If we can escape such a conclusion, we do so only by a presumption. We may admit that the proof that all protoplasm is embued with consciousness is utterly unobtainable We may have to think of this proof as so purely abse may have to think of this proof as so purely abutility which we always demand in our science. If this is so, there is a way of reconciliation.

We may claim, without fear of dispute, that the muscles furnish their quota of the energy of the afferent aspects of the nervous system. It is the movement in and of the muscles, tendons and joints that starts the kinesthetic and other cenesthetic impulses starts the kinesthetic and other cenesthetic impulses
toward the centers. It is the stupendous maze of the central nervous system, on the other hand, that coördi central nervous system, on the other hand, that coorrdi-
nates these multitudes of influences pushing into the gray matter. Our problem resolves itself then int a matter of definitions-as so often happens in science and philosophy.

C๑-๑RdiNATION AND VITALITY THE BUSINESS •F NLRVOU -RGANIZATTON.

No one would think of an isolated muscle or musclefabric even as possessing consciousness. It is only when this portion of muscle-protoplasm is part of a individual that it may be said to have feeling or any phase of mentality. The nervous system is the chief means of coördinating the muscles and other organs of the body. Coördination and vitality, as Morat usefully coins the word, is the sole business of the nervous fully coins the word, is the sole business of the nervou
organization. Without its integrating activities ther could be no personality, no center of conscious or subconscious purposes. Associative memory, the ultimate biologic analysis of mind, could not persist and give the muscles and the epithelium, the bones and the connective tissues usefulness and a nersonality. In this sense, then, namoly as a coördinator and integrator, the central nervous system is undeniably the basis of consciousness. Without it, or its equivalent, personal mentality were unthinkable, for in a chaos, purpose an the other attributes of personality do not inhere

When, however, we trace to its source the energy that directs the movements that in turn represent the stream of consciousness and subconsciousness, we find that of all forms of protoplasm in our bodies none has a better claim to represent the mental process than has muscle.

\section{Poker Explodes}

A sTEAM plant had occasion to use as a poker 10-foot rod made of heavy tubing, one end of which had heen hammered together, the other end being open.
The open end was always thrust back into the coal pile after using with the result that some finely powderec coal found its way inside. It was decided, however, to close the other end also. The next time the poker was used to any extent there was a terrific explosion that tore the poker apart and hurled the fireman against the boiler. It was thought that a quantity
of the powdered coal remained in the tube.-Electrical World.

\section{Propeller Immersion and Efficiency}

IT is not uncommon to hear the opinion expressed that a screw propeller attains higher efficiency when deeply immersed than when it operates near the sur face, and for this reason it is sometimes suggested that submarines may attain better results when submerged than when running on the surface. In many vessels the idea has caused a greater vertical inclination to be given to propeller shafts than is desirable from other points of view. To expect increase of efficiency from mere increase of immersion is quite erroneous. There is no benefit from immersion alone, so long as the speed of slip imparted to the water by a propeller is less than the speed of flow to the screw, which can be produced by the combined pressures due to head of water and atmosphere, and there is no air drawing; indeed, it was pointed out in a paper read before the Institute of Marine Engineers in 1905 that analysis of trials of a number of destroyers carried out in smooth water showed that "the least immersion of the propellers gave the best results, both in speed and coal bill." This has also been found to be the case in vessels of other types. Taylor says in his book, "Speed and Power of Ships," "There is little doubt that, contrary to what is generally supposed, a propeller for smooth water work is more efficient the closer it is to the surface." This superiority is explained by the fact that a propeller near the surface gets more useful reaction from the wake of the ship than one more deeply immersed, for frictional, wave and steam-line wakes ar all strongest near the surface. The wake in this region may be looked upon as existing not only in a layer round the hull of the ship, but also as a shallow stratum spread along the surface, widening as it goes aft. For this reason a propeller near the surface reaps greater advantage from the wake than one more deeply im mersed, while at the same time there is a decided disadvantage in having shafts inclined downwards at the after end to any great extent, for it involves placing the shaft webbing at such an angle to the direction of advance that there is likely to be unnecessary resistance on this account. The disadvantage is aggravated at high speeds if the ship squats by the stern, as is generally the case. There is reason also to think that the propeller itself does not work so efficiently when the inclination of the center of shaft to the line of advance is considerable, for the slip angles of the blades vary to a greater or less degree, depending on position during rotation and degree of inclination of the shaft There is no advantage from immersion to compensate for these disadvantages when a vessel is running in smooth water, but there is the practical consideration of possible racing when in a seaway, which leads many designers to give deep submergence to propellers, and it is a very important feature to bear in mind, apart from the question of efficiency, for the stresses on propeller shafting when a revolving propeller is alternately plunged into and lifted out of the water are very quite justified in many cases, but it is probable that the practice has given rise to a prevalent opinion that depth of immersion is desirable simply for reasons of efficiency. In discussing the effect of immersion we must therefore remember that all other consideration of efficiency may be subsidiary to that of preventing racing in a seaway for any particular service, but it is necessary for a proper understanding of the case that we ignore racing for the time and examine the conditions for smooth water conditions only.

Propulsive effect of a screw propeller is obtained by imparting to a body of water an absolute speed in the sternward direction. This is the fundamental condition, and it involves the necessity for a continuous supply of water to the propeller in order that the flow of feed may be steadily maintained. There are two conditions to consider which may modify speed of supply. If the propeller be partly immersed and the speed in feet per second imparted to the screw race be greater than $\imath^{\prime 2} g h$, where $h$ is the immersion in feet of any point is produced, for the water will not be able to flow quickly enough to the blades to supply their need, there will be direct access of the atmosphere to the blades,
the pressure due to atmospheric head will be lost and efficiency very seriously impaired. Air drawing must not, however, be confused with cavitation, which is similar in appearance but totally dissimilar in character. Regarding the condition of partial immersion of propeller it may be remarked that no loss of efficiency is involved when part of the propeller is out of the water unless and until the speed of slip imparted to the race is greater than $\sqrt{2} g h_{\text {. }}$. There have been cases of ships running in smooth-water conditions, such as river and canal steamers, where a large diameter of propeller, only half immersed, has been deliberately adopted in order to act upon a larger column of water than is obtainable with a smaller propeller wholly immersed, and the results have been satisfactory. The conditions for a propeller so designed are analogous to those of a paddle float, for the speed at which water can flow to a float under the influence of gravity being $\sqrt{ }^{2 g} h$ as before, it is only at a depth $h$ below the water surface which equals $\frac{V^{2}}{2 g}$ that the water will be able to keep in contact with the back of the float, and all parts above this height will be in contact with air, the water surface on the forward side of the float falls until a position of equilibrium is established. The ordinary condition for screw propellers is that of total immersion, and where there is no air-drawing the speed of water and atmosphere, being expressed by

$$
v=\sqrt{2 g(h+32)}
$$

$v$ being speed in feet per second, $h$ the immersion in feet at any point, and 32 being taken as the equivalent height of water column which balances average atmospheric pressure. This 'additional head, although expressed in terms of water column, is due really to pressure of an air column, which is highly elastic and has little or no inertia, so that its effect is probably greater in proportion than that of an actual corresponding head of water. Whether this be so or not, it is evident that the head due to atmosphere is the larger part of the total head available to produce flow of water to the propeller, for the usual immersion is only a few feet. Any change of immersion must therefore have a relatively small effect upon the limiting pressure available. There seems no reason for the opinion that increase of immersion will result in increase of efficiency within the range of speeds of race, for which there is an uninterrupted supply of water to the propeller, but it naturally increases this range. Nlthough the theoretical limit of speed is

$$
\begin{aligned}
& \sqrt{ } 2 \bar{g}(h+32) \\
& \text { that the feed of }
\end{aligned}
$$

it is probable that the feed of solid water to y impaired at a much lower speed. Whatever the actual speed at which the flow becomes discontinuous, the phenomenon which takes place is that which is known as "cavitation," and the point of commencing cavitation may be affected by immersion, for the speed at which more or less vacuous cavities are formed will be slightly advanced, but only slightly, for the velocity of flow due to atmospheric pressure is common to all immersions. It will thus be seen that "cavitation" and "air drawlng" are totally different manifestations and are caused by different conditions.

Water is practically incompressible, and its density is not therefore affected by depth. The reaction of a propeller at 1 foot depth is the same as that at 10 -foot depth, although the pressures are quite different. The same principle governs the amount of surface friction of a ship's hull. The friction per unit area at the water line is the same as that at the keel for the same distance from the bow. Calculations of skin friction depend only on the amount of surface and the length of plane, and not at all on depth of immersion, although the pressures at the water line and the keel are quite different. The controlling factor is incompressibility of water and constancy of its density. The distinction between pressure and density effects is one which seems to confuse beginners. It must therefore be realized that, regarded from the point of view of immersion alone, there is no increase of efficiency obtainable by increasing immersion. On the contrary, the evidence available shows that a greater efficiency is obtained near the surface than at a greater depth, because of increased hull efficiency, but where there are possibilities of air drawing and racing from pitching in a seaway it is essential that the propellers be deeply placed. If there is reason to fear cavitation it may also be desirable to increase immersion in order to raise the limiting rate of flow. These considerations are, however, apart from the suggestion that mere depth of immersion may result in higher efficiency, and unless they are factors in the design, there is no reason for striving after a deep position for the propellers.-The Engineer. 